\title{
RENCANA PENGELOLAAN GREEN BUILDING DENGAN PENDEKATAN BUILDING ENVIRONMENT MANAGEMENT (BEM)
}

\author{
Regina $^{1)}$, Liong Ju Tjung ${ }^{2)}$, Priyendiswara A.B. ${ }^{3)}$ \\ 1)Program Studi S1 PWK, Fakultas Teknik, Universitas Tarumanagara, reginatatang283@gmail.com \\ 2)Program Studi S1 PWK, Fakultas Teknik, Universitas Tarumanagara, jt.liong@pps.untar.ac.id \\ 3)Program Studi S1 PWK, Fakultas Teknik, Universitas Tarumanagara, priyendiswaraa@ft.untar.ac.id
}

\begin{abstract}
Abstrak
Konsep bangunan hijau saat ini semakin banyak diimplementasikan di Indonesia khususnya DKI Jakarta karena semakin maraknya pemanasan global. Beradaptasi dengan perubahan iklim dan semakin banyaknya bangunan tinggi di Indonesia, $\mathrm{GBCl}$ (Green Building Council Indonesia) menyimpulkan bahwa penyebab terbesar dari penggunaan energi yaitu karena penggunaan pada sektor bangunan sekitar $48 \%$, sedangkan $27 \%$ lainnya sektor transportasi, lalu $25 \%$ sektor industri. $\mathrm{GBCl}$ menerapkan sertifikasi berupa "Greenship" sebagaii alat penilai/penentu untuk sebuah bangunan dinilai sebagai Green Building. "Greenship" dipersiapkan oleh $\mathrm{GBCl}$ dengan mempertimbangkan kondisi, karakter alam serta peraturan dan standard yang berlaku di Indonesia. Fokus utama dari Green Building adalah efisiensi energi, namun yang membedakan "Greenship" dengan rating tools lainnya yaitu "Greenship" mempunyai kategori BEM yang berfokus kepada pengelolaan sampah yang dihasilkan oleh gedung. Rating tools berupa "Greenship" di Indonesia cukup seimbang karena selain berfokus pada efisiensi energi, "Greenship" juga memperhatikan unsur kenyamanan penghuninya yaitu dengan adanya kategori Manajemen Lingkungan Bangunan (BEM) dimana kenyamanan penghuni bangunan merupakan salah satu faktor keberhasilan dari green building. Agar suatu green building dapat dikelola secara maksimal, penulis menyusun penelitian pada kriteria BEM (Building Environment Management), dengan rekomendasi untuk pengelolaan sampah dan fit-out di salah satu Green Building di Jakarta yaitu South Quarter dengan pencapaian BEM sebesar $77 \%$. Penulis menyusun biaya anggaran yang disarankan untuk evaluasi pemilahan sampah dan training, penulis juga melakukan survei persepsi tenant dengan metode tabulasi silang dan perbandingan nilai tengah dengan hasil bahwa $77 \%$ responden setuju dengan perencanaan pemilahan sampah dan pengadaan training untuk penghuni gedung di Green Building.
\end{abstract}

Kata kunci: Bangunan Hijau; Greenship; Manajemen Lingkungan Bangunan

\begin{abstract}
The concept of green building is now increasingly being applied in Indonesia, especially DKI Jakarta due to the increasing prevalence of global warming. Adapting to climate change and the increasing number of tall buildings in Indonesia, the $\mathrm{GBCl}$ (Green Building Council Indonesia) concluded that the biggest cause of energy use was due to the use of the building sector of around $48 \%$, while the other $27 \%$ was in the transportation sector, then $25 \%$ in the industrial sector. GBCl applies certification in the form of "Greenship" as an assessment tool for buildings that are rated as Green Buildings. "Greenship" is prepared by GBCl by considering the conditions, nature, rules and standards that apply in Indonesia. The main focus of Green Building is energy efficiency, but what distinguishes "Greenship" from other rating tools are "Greenship" has a BEM category that focuses on managing the waste produced by buildings. The rating tool "Greenship" in Indonesia is quite balanced because in addition to focusing on energy efficiency, "Greenship" also pays attention to the comfort elements of its occupants, namely the Building Environmental Management category (BEM) where the comfort of buildings is one of the factors in the success of green buildings. In order for green building to be managed optimally, the author compiled a study of the criteria for BEM (Building Environment Management), with recommendations for waste and fit-out management in one of Green Building in Jakarta, South Quarter with a BEM achievement of $77 \%$. The author composes the recommended budgetary costs for evaluating waste sorting and training, the author also conducted tenant perceptions surveys with cross tabulation and compare means
\end{abstract}


method with the results that $77 \%$ of respondents agreed with the planning of sorting waste and providing training for residents of the building at the Green Building. the result that $77 \%$ of respondents agreed with planning waste sorting and providing training to building occupants in the Green Building.

Keywords: Building Environment Management (BEM); Greenship; Green Building

\section{PENDAHULUAN}

Pada penelitian ini, saya mengkaji pada lingkup manajemen dari green building yaitu Manajemen Lingkungan Bangunan (BEM) sesuai dengan konsentrasi real estate. Green Building Council Indonesia menerapkan sertifikasi berupa "Greenship" sebagai alat penilai/penentu untuk sebuah bangunan dinilai sebagai Green Building. Greenship dipersiapkan dan disusun oleh $\mathrm{GBCl}$ dengan mempertimbangkan kondisi, karakter alam serta peraturan dan standard yang berlaku di Indonesia. Greenship disusun dengan melibatkan para pelaku sektor bangunan yang ahli di bidangnya seperti arsitek, industri bangunan, teknisi mekanikal elektrikal, desainer interior, arsitek lansekap, dan lainnya. Negara-negara lain yang sudah mengikuti gerakan green building juga memiliki sistem penilaiannya sendiri. Seperti misalnya Amerika Serikat memiliki LEED (Leadership in Energy and Environmental Design), Singapura memiliki Green Mark, dan Australia memiliki Green Star. Dalam pembuatannya, Greenship sebagai perangkat penilaian membutuhkan suatu acuan dan dukungan dari pemerintah. Sehingga Greenship menggunakan kriteria penilaian sedapat mungkin berdasarkan standard lokal baku seperti Undang-Undang (UU), Keputusan Presiden (Keppres), Instruksi Presiden (Inpres), Peraturan Menteri (Permen), Keputusan Menteri (Kepmen), dan Standar Nasional Indonesia (SNI). GBC Indonesia saat ini sudah mengeluarkan 5 jenis GREENSHIP, yaitu :

a. Greenship New Building : sertifikasi dimulai pada tahap perencanaan gedung

b. Greenship Existing Building : sertifikasi dimulai pada tahap operasional gedung

c. Greenship Interior Space : sertifikasi dilakukan dalam lingkup ruang interior

d. Greenship Homes : sertifikasi dilakukan dalam lingkup unit rumah

e. Greenship Neighborhood : sertifikasi dilakukan dalam lingkup lingkungan

Berikut adalah perbandingan rating tools pada masing-masing kategori dari LEED, LEED India, Green Mark, dan Greenship dengan masing-masing alat ukur mempunyai 6 kategori.

Tabel 1. Perbandingan Persentase Kategori Rating Tools di Amerika, India, Singapore dan Indonesia

\begin{tabular}{|c|c|c|c|c|}
\hline Kategori & LEED & $\begin{array}{l}\text { LEED } \\
\text { India }\end{array}$ & $\begin{array}{l}\text { Green } \\
\text { Mark }\end{array}$ & Greenship \\
\hline $\begin{array}{l}\text { Tepat Guna Lahan - Appropriate Site Development } \\
\text { (ASD) }\end{array}$ & $16,5 \%$ & $18,8 \%$ & $20 \%$ & $16,2 \%$ \\
\hline $\begin{array}{l}\text { Efisiensi dan Konservasi Energi - Energy Efficiency } \\
\text { \& Conservation (EEC) }\end{array}$ & $27,1 \%$ & $24,6 \%$ & $35 \%$ & $26,3 \%$ \\
\hline Konservasi Air - Water Conservation (WAC) & $5,9 \%$ & $8,7 \%$ & $15 \%$ & $21,2 \%$ \\
\hline $\begin{array}{l}\text { Sumber \& Siklus Material - Material Resources \& } \\
\text { Cycle (MRC) }\end{array}$ & $18,8 \%$ & $18,8 \%$ & $0 \%$ & $14,1 \%$ \\
\hline $\begin{array}{l}\text { Kualitas \& Kenyamanan Dalam Ruang - Indoor } \\
\text { Health \& Comfort (IHC) }\end{array}$ & $25,9 \%$ & $21,7 \%$ & $15 \%$ & $11,1 \%$ \\
\hline $\begin{array}{l}\text { Manajemen Lingkungan Bangunan - Building \& } \\
\text { Environment Management (BEM) }\end{array}$ & $0 \%$ & $0 \%$ & $0 \%$ & $12,1 \%$ \\
\hline Inovasi - Innovation & $5,9 \%$ & $7,2 \%$ & $15 \%$ & $0 \%$ \\
\hline TOTAL & $100 \%$ & $100 \%$ & $100 \%$ & $100 \%$ \\
\hline
\end{tabular}

Sumber: Naning Adiwoso. Conference on Sustainable Buildings South-East Asia, 2010 
Dari tabel di atas dapat disimpulkan bahwa rating tools mempunyai fokus persentase penilaian masing-masing. Dimana LEED dan LEED India lebih fokus pada efisiensi energi serta kualitas dan kenyamanan dalam ruang, sedangkan Green Mark Singapore lebih fokus pada efisiensi energi serta tepat guna lahan. Fokus Greenship yaitu efisiensi energi dan konservasi air. Sehingga kesimpulannya yaitu fokus utama dari Green Building adalah efisiensi energi. Perbedaan yang signifikan antara Greenship dan rating tools lainnya adalah Greenship tidak mempunyai kategori Inovasi. Namun kategori tersebut digantikan dengan kategori Manajemen Lingkungan Bangunan (BEM) yang tidak dimiliki oleh rating tools lainnya dimana kategori ini berfokus kepada pengolahan sampah yang dihasilkan oleh gedung, yang dipilah berdasarkan jenisnya (organik, anorganik, zat beracun/berbahaya B3) dan dipastikan dikelola secara 3R (reduce, reuse, recycle) yaitu mengurangi, menggunakan kembali, dan mengolah kembali. Hal ini menunjukkan bahwa rating tools green building berupa LEED (Leadership in Energy and Environmental Design) baik di Amerika Serikat dan India lebih seimbang karena tidak hanya fokus pada fisik bangunan, tetapi juga fokus pada kualitas dan kenyamanan udara dalam ruangan yang akan berpengaruh pada kenyamanan penghuni. Sedangkan untuk Green Mark Singapore cenderung lebih fokus pada fisik bangunan karena fokus pada kategori efisiensi energi dan tepat guna lahan. Sedangkan untuk rating tools berupa greenship di Indonesia cukup seimbang karena adanya kategori Manajemen Lingkungan Bangunan yang berpengaruh pada kenyamanan penghuni, dimana kenyamanan penghuni bangunan merupakan salah satu faktor keberhasilan dari green building. Agar suatu green building dapat dikelola secara maksimal, penulis menyusun penelitian pada kategori BEM (Building Environment Management) yaitu salah satu kategori green building tersertifikasi yang hanya dimiliki oleh Greenship.

Dengan rumusan masalah yang akan saya bahas yaitu karena belum adanya rencana pengelolaan dengan kriteria BEM (Building Environment Management) pada Green Building South Quarter serta perolehan kredit BEM 10 poin dari maksimal 13 poin (77\%) sehingga belum maksimal, dan sudah beroperasi 3 tahun setelah sertifikasi.

Tabel 2. Persentase Pencapaian Sertifikasi Green Building

\begin{tabular}{lc}
\hline \multicolumn{1}{c}{ Kriteria } & $\%$ Pencapaian \\
\hline Tepat Guna Lahan - Appropriate Site Development (ASD) & $65 \%$ \\
\hline Sumber \& Siklus Material - Material Resources \& Cycle (MRC) & $36 \%$ \\
\hline Efisiensi dan Konservasi Energi - Energy Efficiency \& Conservation (EEC) & $42 \%$ \\
\hline Kualitas \& Kenyamanan Dalam Ruang - Indoor Health \& Comfort (IHC) & $100 \%$ \\
\hline Konservasi Air - Water Conservation (WAC) & $100 \%$ \\
\hline $\begin{array}{l}\text { Manajemen Lingkungan Bangunan - Building \& Environment } \\
\text { Management (BEM) }\end{array}$ & $77 \%$ \\
\hline
\end{tabular}

Sumber: Olahan Penulis

Tujuan dari penelitian ini adalah untuk melakukan evaluasi pada kategori manajemen lingkungan bangunan (BEM) serta enyusun usulan rencana manajemen dengan kriteria BEM berdasarkan persepsi tenant dan best practices literature $\mathrm{GBCl}$ dengan metode perbandingan.

\section{KAJIAN LITERATUR}

Dalam pencapaian sertifikasi Green Building, menurut Panduan Teknis Perangkat Penilaian Bangunan Hijau untuk Gedung Baru Versi 1.2 terdapat tolok ukur yang harus dipenuhi sebagai persyaratan. Salah satunya yaitu kategori BEM (Building Environment Management). Sehingga 
untuk mencapai kategori ini, terdapat 1 kategori prasyarat dan 7 kategori kredit untuk dipenuhi sebagai salah satu kategori dalam syarat pencapaian sertifikasi Green Building, namun hanya 4 kriteria dalam kategori BEM yang akan dibahas dan ditinjau oleh penulis yaitu 1 kategori yang merupakan prasyarat yang mutlak harus dipenuhi dari Kategori Manajemen Lingkungan Bangunan (BEM) yaitu BEM P Dasar Pengelolaan Sampah dan 3 kategori kredit yaitu BEM 3 Pengelolaan Sampah Tingkat Lanjut, BEM 6 Kesepakatan Dalam Melakukan Aktivitas Fit Out dan BEM 7 Survei Pengguna Gedung.

Keempat kriteria ini pun akan dibahas dan diolah dalam studi ini sehingga penulis akan melakukan evaluasi pada keempat kriteria tersebut. Keempat kriteria ini merupakan kriteria yang masih dapat ditingkatkan pasca-operasional sebuah Green Building. Untuk kriteria lainnya seperti BEM 1 GP Sebagai Anggota Tim Proyek, BEM 2 Polusi dari Aktivitas Konstruksi, BEM 4 Sistem Komisioning yang Baik dan Benar dan BEM 5 Penyerahan Data Green Building. Keempat kriteria ini tidak dibahas dalam penelitian ini karena merupakan kriteria yang dinilai pada saat sertifikasi pra-operasional sebuah Green Building pada saat baru saja selesai dibangun dan dilakukan sertifikasi.

Berikut penjelasan / persyaratan yang harus dilakukan dalam menilai 4 kategori yang masih dapat ditingkatkan berdasarkan Panduan Teknis Perangkat Penilaian Bangunan Hijau untuk Gedung Baru Versi 1.2:

\section{1) Kategori BEM Prasyarat: Manajemen Dasar Sampah (Basic Waste Management)}

Kategori ini bertujuan untuk mendorong gerakan pemilahan sampah secara sederhana yang mempermudah proses daur ulang. Dengan tolok ukur yaitu adanya instalasi atau fasilitas untuk memilah dan mengumpulkan sampah sejenis sampah rumah tangga (UU No. 18 Tahun 2008) berdasarkan jenis organik, anorganik, dan B3.

Banyaknya sampah yang dihasilkan dalam berbagai bentuk dan semakin sempitnya tempat pembuangan akhir atau TPA ditambah dengan masih rendahnya kesadaran pengguna gedung dalam melakukan pemilahan sampah menyebabkan volume sampah yang semakin meningkat dari hasil buangan dalam berbagai bentuk yang tercampur baur. Sampah sejenis sampah rumah tangga merupakan sampah yang berasal dari kawasan komersial, kawasan industri, kawasan khusus, fasilitas sosial, fasilitas umum, dan/atau fasilitas lainnya. Pengelolaan sampah sejenis sampah rumah tangga dimulai dari 3R yaitu pengurangan sampah (reduce) seperti dengan mengurangi penggunaan plastik dan juga penanganan sampah yang terdiri dari pendauran ulang sampah (recycle) menjadi barang yang berguna ataupun mengolah menjadi kompos dan/atau pemanfaatan kembali sampah (reuse) seperti penggunaan kembali botol-botol bekas.

Lingkup dari kriteria ini berupa pemisahan jenis sampah sesuai dengan ketentuan yang berlaku pada UU No. 18 tahun 2008 tentang Pengelolaan Sampah. Dengan menyediakan instalasi atau fasilitas yang dimaksud dalam kriteria ini adalah tong sampah (trash bin) kecil, sedang, maupun besar (disesuaikan dengan volume sampah sesuai dengan jumlah pengguna gedung), tempat pengumpulan sementara (TPS) yang berada di dalam lahan gedung, hingga penampungan utama di gedung. Kriteria ini tidak hanya menilai keberadaan dari fasilitas atau instalasi tersebut, namun juga kejelasan dari proses pemilahan, pengumpulan dan transportasi pengangkutan sampah mulai dari sumbernya pada tiap lantai kerja sampai dengan ke TPS, menuju ke TPA. Seluruh jalannya proses harus dipastikan bahwa sampah tetap terpisah sesuai dengan jenisnya.

Menurut Departemen Perhubungan RI dalam artikel berjudul Sampah: Ancaman Bagi Kawasan Alam yang diunduh 26 Januari 2012, pengertian sampah organik yaitu merupakan sampah yang mudah membusuk seperti sisa makanan, sayuran, daun-daun kering, dan sebagainya. Sampah ini dapat diolah lebih lanjut menjadi kompos misalnya. Sedangkan, sampah anorganik adalah sampah yang tidak mudah membusuk, seperti plastik wadah pembungkus makanan, kertas, plastik, botol dan gelas minuman, kaleng, kayu, dan sebagainya. Sampah ini dapat dijadikan sampah komersil untuk dijadikan produk lain. 
Beberapa sampah anorganik yang dapat dijual adalah plastik wadah pembungkus makanan, botol dan gelas bekas minuman, kaleng, kaca, dan kertas, baik kertas koran, HVS, maupun karton. Menurut Undang-Undang Nomor 32 Tahun 2009 tentang Perlindungan dan Pengelolaan Lingkungan Hidup, limbah B3 (bahan berbahaya dan beracun) adalah zat, energi dan/atau komponen lain yang karena sifat, konsentrasi dan/atau jumlahnya, baik secara langsung maupun tidak langsung, dapat mencemarkan, merusak lingkungan hidup, dan/atau dapat membahayakan lingkungan hidup, kesehatan, kelangsungan hidup, dan/atau dapat membahayakan lingkungan hidup, kesehatan, kelangsungan hidup manusia serta makhluk hidup lainnya ${ }^{1}$. Limbah B3 terkandung pada beberapa barang yang kita gunakan sehari-hari seperti misalnya: baterai bekas, hairspray, pestisida, pembersih lantai, deterjen, obat nyamuk, minyak wangi, sabun cuci piring, aki kendaraan, oli, dsb.

Pemilik gedung menyediakan fasilitas untuk pengguna gedung melakukan pemilahan dalam bentuk pengelompokan dan pemisahan sampah sesuai dengan jenis, jumlah, dan/atau sifat sampah. Lalu, melalui fasilitas yang telah tersedia tersebut, dilakukan pengumpulan dalam bentuk pengambilan dan pemindahan sampah dari sumber sampah ke tempat penampungan sementara atau tempat pengolahan sampah terpadu. Sehingga syarat utama dari kriteria ini yaitu memisahkan fasilitas tempat sampah seperti pada gambar 1. yang menunjukkan contoh fasilitas tempat pembuangan sampah yang telah dipisahkan antara organik dan anorganik dan pemisahan untuk limbah B3.
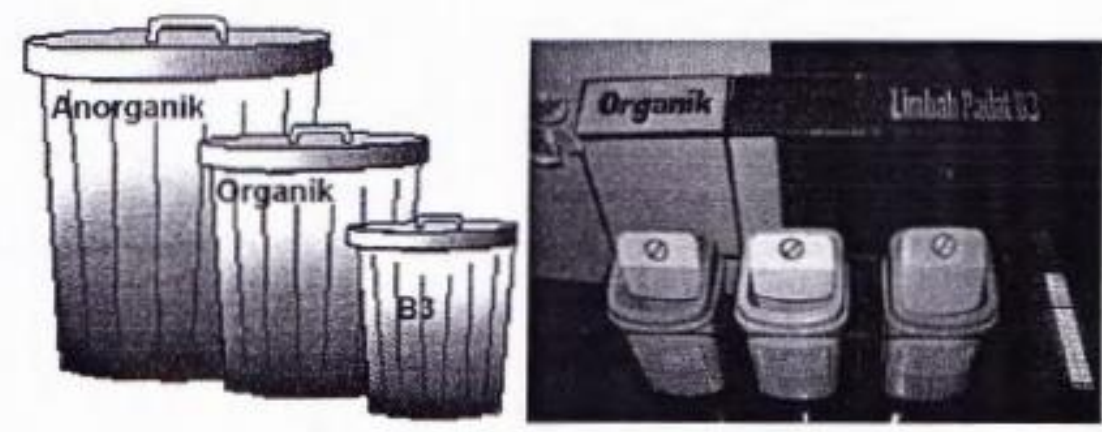

Gambar 1. Contoh Fasilitas Tempat Pembuangan Sampah yang Terpisah menjadi Organik, Anorganik dan B3

Sumber: Panduan Teknis Perangkat Penilaian Bangunan Hijau Untuk Gedung Baru V 1.2 - GBC Indonesia, 2013

\section{2) Kategori BEM Kredit 3: Pengelolaan Sampah Tingkat Lanjut}

Masih sama dengan kategori sebelumnya, tujuan utama dari kategori ini yaitu mendorong gerakan pemilahan sampah secara sederhana yang mempermudah proses daur ulang, dengan tolok ukur yang masih sama yaitu dengan adanya instalasi atau fasilitas untuk memilah dan mengumpulkan sampah sejenis sampah rumah tangga (UU No. 18 Tahun 2008) berdasarkan jenis organik, anorganik, dan B3.

Secara garis besar, lingkup dan opsi kriteria ini adalah mendorong manajemen kebersihan dan sampah secara terpadu sehingga mengurangi beban TPA. Tolok ukur kriteria ini adalah adanya instalasi pengomposan limbah organik baik di lokasi tapak bangunan atau kerjasama dengan pihak ketiga, dan memberikan pernyataan rencana kerjasama untuk pengelolaan limbah anorganik dan limbah b3 dengan pihak ketiga di luar sistem jaringan persampahan kota. 


\section{3) Kategori BEM Kredit 6: Kesepakatan dalam Melakukan Aktivitas Fit-Out}

Tujuan dari kategori ini yaitu mengimplementasikan prinsip green building saat fit out gedung. Dengan tolok ukur memiliki surat perjanjian dengan penyewa gedung (tenant) untuk gedung yang disewakan atau POS (Point of Sale) untuk gedung yang digunakan sendiri yaitu penggunaan kayu yang bersertifikat untuk material fit out dan pelaksanaan pelatihan yang akan dilakukan oleh manajemen gedung.

\section{4) Kategori BEM Kredit 7: Survei Pengguna Gedung}

Tujuan kategori ini yaitu mengukur kenyamanan pengguna gedung melalui survei yang baku terhadap pengaruh desain dan sistem pengoperasian gedung. Dengan tolok ukur memberi pernyataan bahwa pemilik gedung akan mengadakan survei suhu dan kelembaban paling lambat 12 bulan setelah tanggal sertifikasi dan menyerahkan laporan hasil survei paling lambat 15 bulan setelah tanggal sertifikasi kepada GBC Indonesia. Apabila hasilnya $>20 \%$ responden menyatakan ketidaknyamanannya, maka pemilik gedung setuju untuk melakukan perbaikan selambat-lambatnya 6 bulan setelah pelaporan hasil survei.

Namun pada kategori ini penulis tidak melakukan survei suhu maupun kelembaban karena hal ini terkait dengan kategori lain, penulis melakukan survei berupa persepsi pengguna gedung terkait ketiga kategori sebelumnya yaitu evaluasi pengelolaan sampah dan ketentuan fit-out.

\section{METODE}

Untuk mencapai tujuan penelitian yakni membuat rencana pengelolaan BEM berdasarkan persepsi tenant, dan penentuan anggaran biaya terkait kriteria BEM, maka penulis perlu melakukan beberapa analisis dan metode untuk dapat mencapai tujuan tersebut. Analisis dan metode yang digunakan yaitu:

a. Analisis BEM (Manajemen Lingkungan Bangunan)

Analisis ini berupa evaluasi dari kondisi eksisting manajemen lingkungan bangunan pada Kantor South Quarter Green Building. Evaluasi dilakukan dengan metode perbandingan kondisi eksisting dengan standard literatur dari $\mathrm{GBCl}$.

b. Analisis Budget Cost

Pada analisis ini, dilakukan penghitungan biaya anggaran yang diperlukan untuk melakukan evaluasi pengelolaan BEM berupa pengelolaan sampah dan ketentuan fit-out pada Kantor South Quarter Green Building.

c. Analisis Persepsi Tenant

Pada analisis ini, metode yang dilakukan yaitu kuantitatif deskriptif dan perbandingan nilai tengah dimana dengan hasil kuesioner yang disebarkan, akan dilihat persepsi tenant mengenai usulan evaluasi pengelolaan BEM pada Kantor South Quarter Green Building berupa pengelolaan sampah dan ketentuan fit-out.

d. Analisis Evaluasi BEM berdasarkan Persepsi Tenant

Pada analisis ini, akan dideskripsikan evaluasi BEM yang disarankan berdasarkan hasil persepsi tenant.

e. Analisis Rencana Manajemen dengan Kriteria BEM pada South Quarter

Analisis ini merupakan saran dan rekomendasi pengelolaan BEM yang terdiri dari pembiayaan dan hasil persepsi tenant mengenai evaluasi BEM pada Kantor South Quarter Green Building terkait pengelolaan sampah dan ketentuan fit-out.

\section{Teknik Pengumpulan Data}

Dalam melakukan pengumpulan data, diperlukan metode pengumpulan data yang sesuai dengan kebutuhan. Maka diperlukan teknik pengumpulan data yaitu survei lapangan, wawancara, dokumentasi, serta kuesioner. 
Survei lapangan merupakan metode pengamatan langsung pada objek penelitian yang dilakukan oleh peneliti untuk mendapatkan data yang tidak bisa didapatkan dengan cara sekunder. Survei lapangan ini bertujuan untuk mengetahui kondisi lapangan terkini dari objek yang akan diteliti yaitu Kantor South Quarter Green Building. Penulis juga melakukan wawancara dengan pihak terkait yaitu pihak pengelola /building management, tenant relation, serta pihak pengelola yang terkait dengan kriteria BEM pada South Quarter. Dokumentasi berupa bukti foto yang diambil ketika melakukan survei lapangan. Penulis juga melakukan penyebaran kuisioner dimana kuesioner ini diperuntukan pada karyawan-karyawan atau pekerja yang merupakan tenant di kantor South Quarter. Pekerja dikategorikan menjadi 9 jenis berdasarkan bidang usahanya dengan perbandingan sesuai dengan luasan kantor yang disewa. Penyebaran kuesioner ini dilakukan untuk mengetahui preferensi atau keinginan dari tenant mengenai pengelolaan gedung terkait BEM serta saran dan masukan atau persepsi tenant tentang pengetahuan tenant akan BEM serta pilihan atau kecenderungan tenant untuk evaluasi. Pengambilan sampel dilakukan dengan menggunakan teknik stratified random sampling atau acak yaitu cara pengambilan sampel yang memberikan kesempatan yang berbeda sesuai dengan bidang usahanya untuk diambil kepada setiap populasi. Metode pengambilan sampel yang digunakan untuk mengetahui berapa banyak sampel yang akan diambil agar benar-benar dapat dianggap mewakili keseluruhan populasi. Populasi dalam hal ini adalah jumlah seluruh jumlah karyawan pada tenant dari gedung kantor South Quarter yang terbagi dalam jumlah jiwa yaitu terdapat 6.372 jiwa pada seluruh tenant di South Quarter. Perhitungan sampling untuk responden dari total pekerja tenant di South Quarter dan dengan batas toleransi kesalahan maksimal yang penulis tetapkan adalah sebanyak $10 \%$ atau sama dengan tingkat kepercayaan $90 \%$, yaitu 99 responden yang didapat dari perhitungan sample dengan menggunakan perhitungan rumus Slovin dengan waktu penyebaran kuesioner dilakukan pada hari kerja (weekdays).

Responden terbagi menjadi 9 kelompok sesuai dengan bidang usaha kantor masing-masing yang diperkirakan sesuai jumlah unit kantor yang disewa. Berikut adalah perkiraan sasaran responden yang dihitung sesuai dengan jumlah unit masing-masing bidang usaha dengan total unit tersewa yaitu 237 unit. Responden dibagi menjadi demikian agar dapat mewakili keseluruhan unit office.

Tabel 2. Sasaran Responden berdasarkan Bidang Usaha Kantor

\begin{tabular}{lrr}
\hline \multicolumn{1}{c}{ Bidang Usaha Kantor } & Jumlah Unit & Persentase \\
\hline Banking & 79 & $33 \%$ \\
\hline Retail,f\&b,trading company & 46 & $19 \%$ \\
\hline Automotive & 27 & $11 \%$ \\
\hline Pharmaceutical & 18 & $8 \%$ \\
\hline Tobacco & 17 & $7 \%$ \\
\hline Engineering Consultant & 16 & $7 \%$ \\
\hline Hygiene Services / Filtration & 5 & $2 \%$ \\
\hline Lighting, Oil \& Gas and Healthcare & 27 & $11 \%$ \\
\hline Freight Forwarding & 2 & $1 \%$ \\
\hline Total & 237 & $100 \%$ \\
\hline Sumbr: Penuls, 2019
\end{tabular}

Sumber: Penulis, 2019

Setelah melakukan penyebaran kuesioner, penulis berhasil mengumpulkan 120 responden setelah melakukan penyebaran kuesioner, penulis mengambil sample lebih dengan tujuan meningkatkan akurasi hasil penelitian dan meminimalisir error atau kesalahan responden dalam mengisi kuesioner. Untuk mempermudah analisis, bidang usaha kantor dipersempit menjadi bidang industri, jasa dan perbankan. 
Survei persepsi tenant diolah dengan analisis yang terdiri dari 3 analisis menggunakan metode statistik deskriptif crosstab atau tabulasi silang untuk melihat hubungan antara 2 variabel yaitu Analisis Frekuensi Pembuangan Sampah B3 berdasarkan Bidang Usaha Kantor, Analisis Jenis Tempat Sampah di Unit Office berdasarkan Bidang Usaha Kantor, Analisis Status Pendidikan Pekerja Kantor SQ dengan Tingkat Kepahaman Pemilahan Tempat Sampah.

Serta 3 analisis skala likert dengan menggunakan metode compare means atau membandingkan nilai tengah yaitu one sample $T$ test berupa Analisis Tingkat Kepahaman Pekerja Kantor SQ terhadap Pemilahan Tempat Sampah, Analisis Tingkat Kepentingan Desain Tempat Sampah di SQ dan Analisis Tingkat Kepentingan Training di SQ.

\section{DISKUSI DAN HASIL}

Rencana pengelolaan BEM yang dimaksud oleh penulis yaitu berupa usulan evaluasi pengelolaan sampah secara terpilah yang efektif sehingga dapat mengajak pengguna gedung untuk mengerti dan sadar bahwa mereka berada di lingkungan Green Building. Penulis menghitung biaya yang harus dikeluarkan oleh pihak SQ untuk menerapkan pemilahan sampah maksimal dengan menyediakan tempat sampah B3 di setiap public area di SQ dengan anggaran biaya seperti di bawah ini:

Tabel 3. Budget Cost Pengelolaan Sampah

\begin{tabular}{|c|c|c|c|c|c|}
\hline \multirow{2}{*}{ No } & \multirow{2}{*}{ Jenis } & \multirow{2}{*}{ Qty } & \multirow{2}{*}{ Satuan } & \multicolumn{2}{|c|}{ Harga } \\
\hline & & & & Satuan & Total \\
\hline 1 & $\begin{array}{l}\text { Tempat Sampah Stainless } \\
\text { Semi Circle } 30 \text { L (office area) } \\
\text { It } G-10\end{array}$ & $\begin{array}{c}2 \times 9 \text { lantai } \times 3 \\
\text { gedung }\end{array}$ & Set & 380.000 & 20.520 .000 \\
\hline 2 & $\begin{array}{l}\text { Tempat Sampah Stainless } \\
\text { Semi Circle } 30 \text { L (office area) } \\
\text { It } 11-22\end{array}$ & $\begin{array}{c}1 \times 10 \text { lantai } \times 3 \\
\text { gedung }\end{array}$ & Set & 380.000 & 11.400 .000 \\
\hline 3 & $\begin{array}{l}\text { Tempat Sampah SULO } 120 \mathrm{~L} \\
\text { (ruang sampah shaft tiap } \\
\text { lantai office area) }\end{array}$ & $\begin{array}{c}2 \times 19 \text { lantai } \times 3 \\
\text { gedung }\end{array}$ & Set & 940.000 & 107.160 .000 \\
\hline 4 & $\begin{array}{l}\text { Tempat Sampah Stainless } 30 \\
\text { L Lower Ground / Basement } \\
\text { 1, Basement } 2 \text { dan } \\
\text { Basement } 3\end{array}$ & $3 \times 3$ basement & Set & 380.000 & 3.420 .000 \\
\hline 5 & $\begin{array}{l}\text { Tempat Sampah Stainless } \\
\text { Bulat Swing } 25 \text { L Halaman } \\
\text { Gedung }\end{array}$ & 3 & Set & 410.000 & 1.230 .000 \\
\hline 6 & $\begin{array}{l}\text { Tempat Penampungan } \\
\text { Sampah (SULO } 660 \text { L) }\end{array}$ & 1 & pcs & 6.850 .000 & 6.850 .000 \\
\hline & & DTAL & & & 150.580 .000 \\
\hline
\end{tabular}

Sumber: Penulis, 2019

Dari hasil survey kondisi eksisting pada South Quarter mengenai penyediaan tempat sampah yang terpilah menjadi organik dan anorganik, penulis menghitung perkiraan jumlah anggaran biaya dengan saran penambahan tempat sampah B3 untuk setiap area publik dengan sumber harga yaitu sesuai dengan harga tempat sampah yang sudah ada di South Quarter. Selain biaya tambahan yang disarankan oleh penulis, juga terdapat biaya operasional bulanan yang terdiri dari biaya kerjasama dengan pihak ketiga untuk mengolah sampah sebesar Rp 5.500 .000 dan biaya upah housekeeping outsourcing dengan asumsi 50\% dari upah untuk jobdesk mengurus pengolahan sampah yang terpilah yaitu sebesar $\mathrm{Rp} 1.500 .000$ /orang dengan jumlah karyawan cleaning service sebanyak 121 orang sehingga total 50\% upah mereka yaitu sebesar Rp 181.500.000 sehingga total keseluruhan biaya per bulan pada kriteria ini sebesar Rp 187.000.000,-/bulan. 
Selain itu, building management juga harus mengadakan training yaitu sesuai dengan persyaratan kedua dari kategori BEM 6: Ketentuan Fit-Out sehingga pengelolaan BEM dapat terlaksana secara maksimal. Dengan anggaran biaya untuk pelaksanaan training yaitu:

Tabel 4. Budget Cost Training Green Building

\begin{tabular}{llr}
\hline No & Training & Biaya \\
\hline 1 & Training Greenship Associates (Reguler) & 3.000 .000 \\
\hline 2 & Training Greenship Professional (Reguler) & 8.000 .000 \\
\hline & TOTAL & $\mathbf{1 1 . 0 0 0 . 0 0 0}$ \\
\hline
\end{tabular}

Sumber: Penulis, 2019

Sumber dana terkait hal ini akan diajukan oleh Design and Engineering Manager dan Deputy General Manager Building Management South Quarter kepada Finance. Hal ini bertujuan untuk memenuhi syarat sertifikasi yang maksimal pada Green Building. Personil yang disarankan oleh penulis untuk melakukan training tersebut yaitu Fit-Out Supervisor dan Tenant Relation Supervisor. Setelah building management mengikuti training di $\mathrm{GBCl}$, tim $\mathrm{BM}$ dapat mengadakan training yang dapat dilakukan di function hall yang terletak di LG Dome Retail South Quarter setiap 3 bulan sekali sehingga dapat mengedukasi tenant yang ada di SQ dengan jumlah karyawan sebanyak 6.372 jiwa. Adapun hal yang wajib disampaikan dalam training kepada tenant atau penghuni gedung menurut syarat BEM yaitu kewajiban tenant dalam mengikuti panduan green building termasuk di dalamnya menggunakan bahan ramah lingkungan seperti kayu legal bersertifikat, kemudian ikut serta dalam pengelolaan sampah yaitu membuang sampah sesuai dengan pemilahannya.

Penulis juga mengadakan survei persepsi tenant dengan hasil berupa :

Responden sebanyak $77 \%$ menyatakan bahwa mereka mengetahui pemilahan sampah berdasarkan syarat green building, namun pada umumnya hanya sekedar cukup paham mengenai pemilahan jenis tempat sampah, sehingga desain pemilahan tempat sampah yang jelas dan mudah dimengerti serta training mengenai pemilahan tempat sampah harus dilakukan. Walaupun sampah B3 jarang dan bahkan nyaris tidak pernah dihasilkan, terdapat $22 \%$ responden yang menyatakan bahwa unit office mereka menyediakan pemilahan sampah menjadi organik, anorganik dan B3 dimana menunjukkan bahwa sudah ada unit office yang memulai pemilahan sampah sesuai kaidah BEM pada green building. Namun 63\% responden menyatakan bahwa mereka tidak cukup paham dengan pemilahan jenis sampah, sehingga hal ini menunjukkan adanya potensi atau pentingnya desain pemilahan tempat sampah serta adanya training pada South Quarter green building. Dengan prioritas menurut persepsi responden yaitu desain pemilahan tempat sampah harus terlebih dahulu dilakukan atau lebih penting sebelum melakukan training. $77 \%$ responden menyatakan bahwa mereka setuju dengan pemilahan sampah yang terbagi menjadi 3 yaitu organik,anorganik dan B3. Mereka percaya dengan pemilahan sampah menjadi 3 jenis ini adalah pemilahan yang paling efektif, dengan cara yang paling efektif yaitu desain tempat sampah terpilah harus jelas dan mudah dipahami disertai dengan visual contoh sampah sesuai jenisnya, serta training juga penting untuk dilakukan agar pengguna gedung juga dapat ikut serta dalam mencapai kesuksesan green building terkait kategori BEM. 


\section{KESIMPULAN DAN SARAN}

Menurut hasil survei persepsi tenant dan saran oleh penulis disimpulkan bahwa perencanaan ini dilakukan secara periodikal yaitu dengan urutan seperti di bawah ini:

a. Adanya penyediaan jenis tempat sampah terpilah berdasarkan organik, anorganik dan B3 pada setiap area publik South Quarter, serta merencanakan desain tempat sampah yang jelas dan mudah dipahami seperti misalnya memberian stiker gambar berupa contoh dari masing-masing sampah sesuai jenisnya seperti yang sudah diterapkan pada MRT Jakarta

b. Mendaftarkan fit-out supervisor dan tenant relation supervisor untuk mengikuti training yang diselenggarakan oleh Green Building Council Indonesia. Kemudian South Quarter dapat menyelenggarakan training akan pengelolaan sampah, penggunaan material dan peralatan ramah lingkungan yang dianjurkan pada sebuah green building, dengan latar belakang yaitu maraknya isu lingkungan yang terjadi agar South Quarter dapat terbukti dengan jelas menerapkan kriteria-kriteria yang ada pada sertifikasi green building sehingga mempunyai nilai sertifikasi maksimal dan menaikkan daya saing dari South Quarter dibandingkan dengan perkantoran green building lainnya. Setelah building management mengikuti training di $\mathrm{GBCl}$, tim BM dapat mengadakan training yang dapat dilakukan di convention hall yang terletak di LG Dome Retail South Quarter setiap 3 bulan sekali sehingga dapat mengedukasi tenant yang ada di SQ dengan jumlah karyawan sebanyak 6.372 jiwa.

c. Biaya yang harus dikeluarkan untuk hal ini diperkirakan sebesar Rp 150.580.000,- untuk penyediaan tempat sampah terpilah berdasarkan organik,anorganik dan B3, dengan biaya operasional BEM sebesar Rp 187.000.000,-/bulan. Serta Rp 11.000.000,- untuk pendaftaran 1 orang perwakilan dari tim building management untuk mengikuti training green building. Sehingga total dari biaya anggaran yang disarankan oleh penulis sebesar Rp 161.580.000,dan biaya operasional sebesar Rp 187.000.000/bulan.

\section{REFERENSI}

Adiwoso, N. (2010, May). New Green Opportunities and Challenges: Towards Indonesia's Sustainable Future through Sustainable Building and Construction. Paper presented at the Conference on Sustainable Buildings South-East Asia, Kuala Lumpur, Malaysia.

Departemen Perhubungan RI. Sampah: Ancaman Bagi Kawasan Alam. Retrieved January 26, 2012, from

http://www.dephut.go.id/INFORMASI/SETJEN/PUSSTAN/info_5_1_0604/isi_4.htm

Green Building Council Indonesia. (2013). Panduan Teknis Perangkat Penilaian Bangunan Hijau untuk Gedung Baru Versi 1.2.

Peter, M. (2004). Service operations management as a conceptual framework for facility management. Facilities, 344-348.

Reed, B. W. (2009). International Comparison of Sustainable Rating Tools.

Samer. (2013). Towards the implementation of the Green Building concept in agricultural buildings: a literature review. Agricultural Engineering International: CIGR Journal, 15(2), 25-46.

Sikdar. (2014). Maintenance and repair of buildings.

Sugiyono. (2008). Metode Penelitian Kuantitatif Kualitatif dan R\&D. Bandung.

Undang-Undang Nomor 18 tentang Pengelolaan Sampah. (2008).

Undang-Undang Nomor 32 tentang Perlindungan dan Pengelolaan Lingkungan Hidup. (2009). 